\title{
Chapter 19 \\ Reconceptualising Exclusion from Civic Engagement in Later Life: Towards a New Research Agenda
}

\author{
Rodrigo Serrat, Thomas Scharf, and Feliciano Villar
}

\subsection{Introduction}

Social exclusion in later life remains a major challenge for ageing societies. Despite widespread acceptance of the multidimensional nature of exclusion in later life, research and policy debates have tended to focus on exclusion from material resources or social relations, often overlooking other recognised dimensions of social exclusion. In this context, and as outlined by Torres when introducing this section (Chap. 18), exclusion from civic engagement has been by far the least studied dimension of social exclusion in later life (Walsh et al. 2017). Older people's civic engagement has been highlighted as a key feature in policy debates around participatory democracy (Barnes et al. 2011) as well as in initiatives aimed at promoting active and successful ways of ageing (United Nations 2002; WHO 2002) or implementing age-friendly communities (Buffel et al. 2012). While research on the topic has grown steadily since the 1960s, many areas remain in need of improvement (Serrat et al. 2019). In this chapter, we argue that research and policy initiatives that are aimed at reducing exclusion around older people's civic engagement should consider four interrelated and often disregarded aspects. First, we need to embrace the multidimensionality of the concept of civic engagement, which includes a range of qualitatively different activities. Second, it is necessary to account for the diversity of the older population, since this shapes who is, in practice, able to engage civically and in which ways individuals are able to participate. Third, attention should be paid to the dynamics and experiences of engagement across the life course, in order to understand better the causes and consequences of civic

\author{
R. Serrat $(\bowtie) \cdot$ F. Villar \\ Department of Cognition, Development and Educational Psychology, \\ University of Barcelona, Barcelona, Spain \\ e-mail: rserrat@ub.edu \\ T. Scharf \\ Population Health Sciences Institute, Newcastle University, Newcastle upon Tyne, UK
}

(C) The Author(s) 2021

K. Walsh et al. (eds.), Social Exclusion in Later Life, International Perspectives

on Aging 28, https://doi.org/10.1007/978-3-030-51406-8_19 
engagement trajectories as people age. Fourth, we need to consider exclusion from civic engagement as a culturally-embedded process that is shaped by the particular socio-political context in which engagement occurs. Before reviewing these four aspects, we explore how civic engagement has been conceptualised and comment on the scope and nature of the evidence available. To develop these points, we draw on the findings of a recent scoping review on older people's civic engagement (Serrat et al. 2019), which allows us to show the four key gaps that future studies should address.

\subsection{Conceptualising Civic Engagement}

Civic engagement is an inherently multidimensional concept that embraces a broad repertoire of activities (Hustinx and Denk 2009). While civic engagement was initially restricted to the act of voting in elections, in recent decades the number of activities considered as civic has expanded rapidly (van Deth 2001). Understandings of civic activities now typically include contacting political representatives, participating in political organisations, being involved in protest activities or social movement organisations, volunteering, or engaging in charitable work. This rapid expansion has transformed civic engagement into an umbrella concept that encompasses a highly diverse range of activities, which may blur its definition and limits. Consequently, its utility both as a tool for exploring and comparing civic activities across empirical studies and as a social policy framework to promote older people's active involvement in community life may be challenged (Theocharis 2015). To avoid such imprecision, there have been numerous attempts to provide systematic criteria to define and organise the diversity of civic activities (e.g. Adler and Goggin 2005; Ekman and Amnå 2012).

Civic activities can be classified according to their objective and format. Consideration of the activity's objective allows us to distinguish between volunteering and political engagement. While volunteering includes activities aimed at helping others or producing common good, political engagement combines activities that are explicitly aimed at influencing decision-making processes on political issues. While most scholars generally agree upon this differentiation, volunteering has sometimes been labelled as social or community engagement (e.g. Ekman and Amnå 2012; Barrett and Brunton-Smith 2014). However, the specific activities that should be included under these two forms of civic engagement remains open to debate, suggesting the need to consider a further axis of classification.

Consideration of the activity's format permits a differentiation between formal or informal volunteering, and between institutionalised or non-institutionalised forms of political engagement. As noted by Jones and Heley (2016):

' $\ldots$ formal volunteering encompasses those activities conducted under the auspices of formal organisations and programmes. Informal volunteering refers to engaging in activities without the umbrella of a prescribed organisation, and includes undertakings that benefit family and friends.' (p. 182) 
In the case of political engagement, that distinction echoes the traditional dichotomy between conventional forms of engagement, such as working on campaigns, contacting political representatives or participating in political organisations or forums, and non-conventional activities, such as signing petitions, boycotting or participating in protest activities or new social movements (Offe 1985). While the former refers to activities channelled by recognised regulated political agents and procedures, the latter encompasses less formal, bottom-up forms of political engagement. So, exclusion from civic engagement refers to older people's inability to engage in informal and formal activities aimed at seeking improved benefits for others, the community, or wider society, or impacting on collective decision-making processes.

\subsection{Assessing the Scope and Nature of Research on Older People's Civic Engagement}

A recent scoping review of research on older people's civic engagement identified not only a substantial growth in publications relating to this topic since the 1960s, and especially since the late 1990s, but also highlighted some key features of the 429 English-language papers that met the review's inclusion criteria (Serrat et al. 2019). ${ }^{1}$ The overwhelming majority of papers included in the review (83\%) focused on collective forms of social engagement, primarily volunteering. Such papers considered, for example, older people's engagement in a broad array of volunteering organisations, including health, educational, social, religious, entrepreneurial, and community organisations. Far fewer papers addressed collective forms of political engagement (13\%; mainly engagement in political organisations or forums or in social movements) or considered individual forms of political engagement $(11 \%$; primarily with a focus on voting behaviours) or of social engagement (6\%; mainly exploring informal helping behaviours outside the family). More than half of the papers included in the review drew on US samples (55\%), with studies conducted in other western nations such as Australia (7\%), the United Kingdom (4\%), Canada (4\%), The Netherlands (3\%) and Spain (3\%) lagging well behind. Only a handful of papers considered civic engagement of older people in non-western nations.

In relation to the process of civic engagement, most papers considered by Serrat et al. (2019) in their scoping review focused on antecedents of engagement (61\%).

\footnotetext{
${ }^{1}$ Searches were conducted in four databases (Psycinfo, Sociological Abstracts, Web of Science, and Scopus) using the following keywords: (Ageing OR Aging OR Aged OR Old age OR older people OR older persons OR older adults OR seniors OR senior citizens OR elder* OR later life OR third age) AND (all the combinations between civic OR civil OR citizen* OR political OR social OR community AND participation OR engagement OR involvement, OR volunteering). Searches were limited to empirical, review, or conceptual/theoretical papers written in English. We did not use any year of publication limit. Searches were carried out in April 2017 and updated in May 2018.
} 
This was especially the case in terms of papers considering individual forms of political engagement (100\%; exploring, for example, the association of such engagement with human and social capital variables (e.g. Nygård and Jakobsson 2013), political attitudes or public policy changes) and collective forms of political engagement ( $85 \%$; assessing, for example, the association of engagement with such aspects as human and social capital, motivations, political attitudes, political generation, or personality variables). While just under two-fifths of papers $(37 \%)$ addressed outcomes of civic engagement, this proportion varied significantly across the different types of civic activity. Studies addressing older people's experiences of engagement were far less frequent (14\%), with most of these considering collective forms of social engagement. Finally, it is important to note that, with some exceptions (e.g. Postle et al. 2005; Tang et al. 2009), most papers did not use social exclusion as a frame of reference to analyse older people's civic engagement.

\subsection{Developing a New Research Agenda on Older People's Civic Engagement}

Although research into older people's civic engagement has significantly increased in recent decades (Serrat et al. 2019) as have studies on social exclusion in later life (Walsh et al. 2017), the two strands of literature have hardly overlapped. Drawing on the scoping review concerning engagement in civic activities in later life (Serrat et al. 2019), we propose that there are four key dimensions that future research should address in order to understand older people's exclusion from these activities: the multidimensionality of civic engagement; the diversity of the older population; the dynamics and experiences of engagement across the life course; and the culturally-embedded process that characterises civic engagement. These four areas underpin a conceptual framework aimed at guiding future studies and policy initiatives aimed at reducing exclusion from civic engagement in later life (Fig. 19.1).

\subsubsection{Multidimensionality of Exclusion from Civic Engagement}

To move research on older people's civic engagement forward implies broadening the concept's meaning. As suggested by Greenfield (2010), definitions have important practice and social policy consequences, as they “... serve to identify not only the what is, but also the what could be and the what should be" (p. 6). Gerontological research has tended to equate civic engagement with volunteering, overlooking the many other ways in which older people engage. Although this trend may reflect the growing interest in older people as active contributors to ageing societies (United Nations 2002; WHO 2002), it also risks embedding cultural expectations regarding what it is to be a good old person and a good old citizen (Martinson and Halpern 


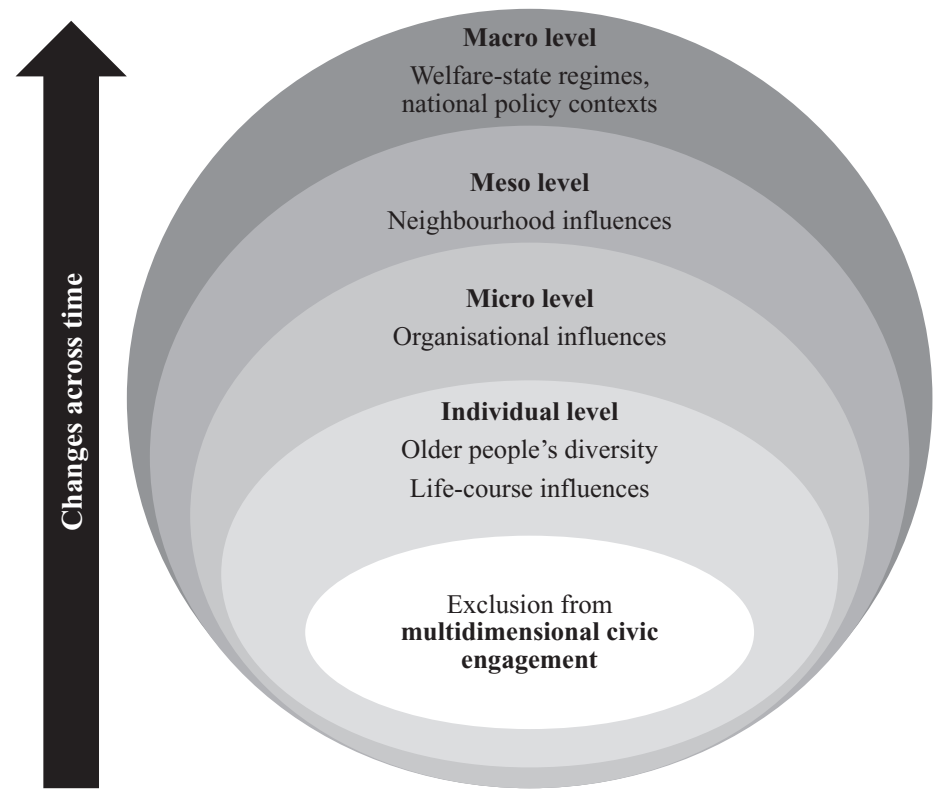

Fig. 19.1 Proposed conceptual framework for studying exclusion from civic engagement in later life

2011), naturalising formal volunteering as the "right" way to contribute. This approach may lead to the stigmatisation of people who are unable or unwilling to formally volunteer, and also to the invisibility of those who engage through other channels (Martinez et al. 2011). Such circumstances also illustrate how processes and cultures associated with dominant discourses of voluntarism may function to exclude older people who engage civically in different ways. Consequently, studies on exclusion from civic engagement in later life may benefit from paying greater attention to informal helping behaviours inside and outside the family, and to political engagement.

It is the relative invisibility of these informal helping behaviours in the ageing literature that is paradoxical, given the fact that caregiving to family members and helping non-kin are far more common among older people than formal volunteering (e.g. Kruse and Schmitt 2015). Critical gerontologists have highlighted that this responds to a gendered construction of what should and what should not be considered civic engagement (e.g. Martinson and Halpern 2011; Nesteruk and Price 2011). This also connects with other forms of social exclusion in later life, such as identity and symbolic exclusion, as valuing some contributions and labelling them as "civic" over others could lead to the depreciation and marginalisation of those who engage in different ways. As noted by Herd and Meyer (2002), if the concept includes activities seeking improved benefits for others, the community, or wider society "... what could possibly fit these definitional requirements better than care work?" (p. 674). Although researching informal helping behaviours may be more challenging than studying formal volunteering, given that they are less easy to quantify, more likely to 
occur in a private sphere, and less likely to be recognised as civic activities by those who perform them, they are of greatest significance for creating and maintaining the social glue, especially among people at greater risk of exclusion in later life, such as people ageing in rural communities (Jones and Heley 2016), older migrants (Torres and Serrat 2019), or the oldest old (Kruse and Schmitt 2015).

As well as considering ways other than formal volunteering in which older people contribute to create and maintain welfare-state systems, we need to take into account their role as supporters or contesters of the rules and values governing these systems. Compared to the considerable body of research on volunteering by older people, studies addressing their engagement in decision-making processes are relatively scarce. These include seminal works on older people's institutionalised political activities (e.g. Jirovec and Erich 1992), but also more recent studies addressing older adults' engagement in social movement organisations (Schwarz 2019) or in seniors' interest organisations (Serrat et al. 2018). Overall, this line of research helps to counterbalance a prevailing apolitical approach to civic engagement in later life, allowing a more nuanced picture in which older people are not only seen as social actors but also as political agents whose voices must be heard in decisionmaking processes at multiple levels.

\subsubsection{Diversity of the Older Population}

Broadening the scope of civic engagement also offers scope to acknowledge the growing diversity of the older population, and therefore the many forms in which older adults engage outside formal volunteering. This not only provides the basis to recognise and value equally all older people's contributions, but also foregrounds the power imbalances that govern later life. Consequently, a second strategic direction for research into civic engagement in later life places the spotlight on older people's diversity. Although social gerontology discourse has increasingly emphasised the importance of considering this diversity, it has been scarcely explored in empirical studies (Stone et al. 2017), and particularly in those addressing civic engagement in later life (Serrat et al. 2019). This is partially due to the omission or underrepresentation in household surveys of some people most at risk of social exclusion (Levitas et al. 2007). Diversity shapes aspects such as who takes part (Petriwskyj et al. 2017) and who benefits from engagement (Morrow-Howell et al. 2009), or in which ways older people participate (Nesteruk and Price 2011). Research and policy initiatives aimed at reducing older people's exclusion from civic engagement may consider the particular challenges that potentially marginalised groups of older people may confront to their full inclusion in civic activities, including older migrants (Torres and Serrat 2019), older people living in long-term care institutions (Villar et al. in this volume), the oldest old (Kruse and Schmitt 2015), or older people experiencing health problems or disabilities (Principi et al. 2016).

Research into older people's exclusion from civic engagement may particularly benefit from simultaneously taking into account multiple dimensions of diversity. Intersectionality theory highlights that people occupying particular social positions 
experience the non-additive effects of multiple forms of inequality. As argued by Calasanti and Kielcot (2012), age may be considered as a system of inequality as “... membership in age categories shape self-concepts and interactions in ways that have material consequences and thus influence life chances" (p. 271). Consideration of diversity in studies on civic engagement must therefore take into account how age interacts with other systems of inequalities, such as gender, disability, living situation, or migrant status, to shape older people's inclusion or exclusion from civic engagement.

Acknowledging older people's diversity has a direct impact on practice and social policy initiatives, raising questions about issues of representation and representativeness. Barnes and Newman (2003), among others, warn about the risks of using a single identity category (such as "older people") to determine how public actors are defined. This raises questions about how diverse groups of older people can be taken into account in decision-making processes, and also regarding which voices represent (and which do not) those who effectively gain a seat at the table (Petriwskyj et al. 2014). As argued by Barnes et al. (2011):

'...the question of whether participants can be considered legitimate representatives of older people requires consideration of the basis on which they might be able to 'speak for' older people who are not directly involved, and whether they can and should be accountable to them.' (p. 263)

Against this background, diversity should be prioritised both in future research aimed at understanding civic engagement and in social policy initiatives seeking to encouraging greater engagement of older people and to reduce opportunities for exclusion from civic activities in later life.

\subsubsection{Exclusion from Civic Engagement as a Culturally-Embedded Process}

Exclusion from civic engagement in later life should be understood as a culturallyembedded process, as it is decisively influenced by where and when engagement occurs. However, this contextual aspect of civic engagement has been underexplored in previous research (Serrat et al. 2019). In order to move research on older people's civic engagement, and their exclusion from that engagement, forward, we should consider at least three possible levels in which exclusion from civic engagement may occur: micro (related to organisational influences), meso (connected to neighbourhood and communities influences), and macro (referring to the influence of welfare-state regimes and national policy contexts).

At the micro level, an emerging body of studies has shown that organisations play a key role in aspects such as recruiting and retaining older people (Devaney et al. 2015) or even the benefits they obtain from their engagement (Hong and Morrow-Howell 2013). Importantly, exclusionary processes are also in place within organisations. This means that some older people may be excluded from civic engagement altogether, while others gain a seat at the table but experience that their 
contributions are not as valued as those of others. According to Young (2000), when organisations are inaccessible to older people because of individuals' physical or cognitive needs, their socio-economic status or their literacy level, then external exclusion takes place. When those who access organisations do not participate in the ways expected, and their opinions are considered less important, internal exclusion occurs. Notwithstanding recent efforts to incorporate an institutional approach into the study of older people's civic engagement (Hong et al. 2009), there is clearly a need for more research addressing these organisational influences.

At the meso level, it is important to consider how neighbourhood and community aspects shape older people's opportunities and constraints for civic engagement [see Tournier and Vidovićová, this volume], as well as the way in which micro organisations are often embedded in particular neighbourhood and community contexts. Recent studies on urban settings show that older people's engagement in formal volunteering is associated with objective municipality characteristics as well as with people's perceptions of social and physical features of their neighbourhood, including connectedness, satisfaction, security, and availability of services and amenities (Dury et al. 2016; Gonzales et al. 2016; see also Urbaniak et al. this volume). Moreover, studies in rural communities highlight the many civic contributions of older people living in these settings, both at formal and informal levels, but also the particular constraints and limitations that rural elders must face to engage civically (Skinner and Hanlon 2015; Jones and Heley 2016; Warburton and Winterton 2017). However, there is clearly a need for more studies analysing the role of spatial aspects on exclusion from civic engagement in later life.

Finally, at the macro level, civic engagement is decisively influenced by the particular socio-political context in which engagement occurs (Goerres 2009). Until fairly recently, most literature on civic engagement in later life emanated from the United States. However, more recent studies focus on other world regions with quite different political and cultural contexts. These include findings from different countries of Europe (Principi et al. 2014) and Asia (Morrow-Howell and Mui 2012), and emerging comparisons across countries in different world regions (Serrat et al. 2018). This body of literature highlights the crucial importance of understanding the macro context when addressing older people's exclusion from civic engagement. It is particularly relevant to explore how different welfare state (Warburton and Jeppsson Grassman 2011) or policy (Castles and Obinger 2008) regimes shape seniors' possibilities for civic engagement. However, research from this perspective remains underdeveloped.

\subsubsection{Dynamics and Experiences of Older People's Exclusion from Civic Engagement}

Finally, civic engagement should be understood as a dynamic rather than static phenomenon, as people may be included or excluded from civic engagement at different points of the life course. Yet most existing research focuses exclusively on later 
life circumstances, and therefore fails to explain how civic engagement begins and develops across the life course (Serrat et al. 2019). Moreover, people may experience changes that reach beyond simply moving in and out of engagement. For example, the ways in which individuals engage or their level of commitment may change over time. However, biographical aspects of civic engagement in later life has been scarcely explored in previous research (Serrat and Villar 2019).

When addressing dynamic aspects of civic engagement, it is useful to distinguish between age-graded influences (i.e. changes associated with particular developmental trajectories), history-graded influences (i.e. historical events and changes that affect specific cohorts of older people), and non-normative influences (i.e. positive and negative events that the individual cannot anticipate) (Baltes 1987; Heckhausen 1999). Regarding history-graded influences, for instance, many western nations are currently experiencing the ageing of the 1968 "generation", people largely in their late teens and early twenties who engaged in non-conventional forms of political protest in the late 1960s. People belonging to this birth cohort may well be engaged in different types of civic activity compared to previous or later cohorts, a point argued by Bruns et al. (2007) in relation to the situation in Germany.

As well as dynamics of civic engagement, experiences of engagement have been largely overlooked in research (Serrat et al. 2019). Studies on the experiences of engagement are aimed at overcoming the idea of civic engagement as a "black box" which older people enter if they have the resources, motivations, and opportunities (antecedents), and which they exit with increased levels of health and well-being (outcomes). Thus, this line of research is aimed at taking a closer look at the experiences and processes occurring inside the "black box" of civic engagement. Most of this research addresses issues of retention, that is, longer permanence within activities and organisations (Tang et al. 2009; Devaney et al. 2015), with a smaller number of studies exploring the informal learning processes occurring through engagement in civic activities and organisations (Piercy et al. 2011; Chen 2016). However, there are still significant opportunities for further studies addressing older people's negative and positive experiences of civic engagement and their role in issues such as retention, satisfaction, or benefits accruing from the activity.

\subsection{Conclusion}

In this chapter, we have sought to make a contribution to conceptual understandings of social exclusion in later life by focusing our attention on the exclusion from civic engagement as the least studied dimension of older people's social exclusion. Drawing on a state-of-the-art review of evidence concerning older people's engagement in civic activities, we make the case that future research should address four key dimensions of older people's exclusion from civic engagement: the multidimensionality of civic engagement; the diversity of the older population; the dynamics and experiences of engagement across the life course; and the culturally-embedded process that characterises civic engagement. In exploring these dimensions of 
exclusion from civic engagement, there is clearly further merit in considering the ways in which this particular form of social exclusion interacts with other forms of disadvantage, thereby exacerbating experiences of exclusion in later life for individuals or groups of older adults.

\section{Editors' Postscript}

Please note, like other contributions to this book, this chapter was written before the COVID-19 pandemic of 2020. The book's introductory chapter (Chap. 1) and conclusion (Chap. 34) consider some of the key ways in which the pandemic relates to issues concerning social exclusion and ageing.

Acknowledgement This work was supported by Spain's Ministry of Economy and Competitiveness, Reference PSI2016-77864-R. Rodrigo Serrat is a Serra Húnter Tenure-Track Lecturer.

\section{References}

Adler, R. P., \& Goggin, J. (2005). What do we mean by "civic engagement"? Journal of Transformative Education, 3(3), 236-253. https://doi.org/10.1177/1541344605276792.

Baltes, P. B. (1987). Theoretical propositions of life-span developmental psychology: On the dynamics between growth and decline. Developmental Psychology, 23(5), 611-626. https:// doi.org/10.1037/0012-1649.23.5.611.

Barnes, M., \& Newman, J. (2003). Constituting "the public" in public participation. Public Administration, 81(2), 379-399. https://doi.org/10.1111/1467-9299.00352/full.

Barnes, M., Harrison, E., \& Murray, L. (2011). Ageing activists: Who gets involved in older people's forums? Ageing and Society, 32(2), 261-280. https://doi.org/10.1017/S0144686X11000328.

Barrett, M., \& Brunton-Smith, I. (2014). Political and civic engagement and participation: Towards an integrative perspective. Journal of Civil Society, 10(1), 5-28. https://doi.org/10.108 0/17448689.2013.871911.

Bruns, P., Bruns, W., \& Böhme, R. (2007). Die Altersrevolution: wie wir in Zukunft alt werden. Berlin: Aufbau-Verlag.

Buffel, T., Phillipson, C., \& Scharf, T. (2012). Ageing in urban environments: Developing "age-friendly" cities. Critical Social Policy, 32(4), 597-617. https://doi. org/10.1177/0261018311430457.

Calasanti, T., \& Kielcot, K. (2012). Intersectionality and aging families. In R. Blieszner \& V. Bedford (Eds.), Handbook of families and aging (pp. 398-434). Santa Barbara: Praeger.

Castles, F. G., \& Obinger, H. (2008). Worlds, families, regimes: Country clusters in European and OECD area public policy. West European Politics, 31(1-2), 321-344. https://doi. org/10.1080/01402380701835140.

Chen, L. K. (2016). Not just helping: What and how older men learn when they volunteer. Educational Gerontology, 42(3), 175-185. https://doi.org/10.1080/03601277.2015.1085786.

Devaney, C., Kearns, N., Fives, A., Canavan, J., Lyons, R., \& Eaton, P. (2015). Recruiting and retaining older adult volunteers: Implications for practice. Journal of Nonprofit \& Public Sector Marketing, 27(4), 331-350. https://doi.org/10.1080/10495142.2015.1015373. 
Dury, S., Willems, J., De Witte, N., De Donder, L., Buffel, T., \& Verté, D. (2016). Municipality and neighborhood influences on volunteering in later life. Journal of Applied Gerontology, 35(6), 601-626. https://doi.org/10.1177/0733464814533818.

Ekman, J., \& Amnå, E. (2012). Political participation and civic engagement: Towards a new typology. Human Affairs, 22(3), 283-300. https://doi.org/10.2478/s13374-012-0024-1.

Goerres, A. (2009). The political participation of older people in Europe: The greying of our democracies. Basingstoke: Palgrave Macmillan.

Gonzales, E., Shen, H. W., Wang, Y., Martinez, L. S., \& Norstrand, J. (2016). Race and place: Exploring the intersection of inequity and volunteerism among older black and white adults. Journal of Gerontological Social Work, 59(5), 381-400. https://doi.org/10.1080/01634372.201 6.1224787.

Greenfield, E. A. (2010). Identifying the boundaries and horizons of the concept of civic engagement for the field of aging. In L. Carstensen, G. O'Neill, \& S. Wilson (Eds.), Civic engagement in an older America (pp. 4-12). Washington, DC: The Gerontological Society of America.

Heckhausen, J. (1999). Developmental regulation in adulthood: Age-normative and sociostructural constraints as adaptative challenges. Cambridge: Cambridge University Press. https:// doi.org/10.1017/CBO9780511527852.

Herd, P., \& Meyer, M. H. (2002). Care work invisible civic engagement. Gender and Society, 16(5), 665-688. https://doi.org/10.1177/089124302236991.

Hong, S., \& Morrow-Howell, N. (2013). Increasing older adults' benefits from institutional capacity of volunteer programs. Social Work Research, 37(2), 99-108. https://doi.org/10.1093/ swr/svs028.

Hong, S., Morrow-Howell, N., Tang, F., \& Hinterlong, J. (2009). Engaging older adults in volunteering: Conceptualizing and measuring institutional capacity. Nonprofit and Voluntary Sector Quarterly, 38(2), 200-219.

Hustinx, L., \& Denk, T. (2009). The "black box" problem in the study of participation. Journal of Civil Society, 5(3), 209-226. https://doi.org/10.1080/17448680903351693.

Jirovec, R., \& Erich, J. (1992). The dynamics of political participation among the urban elderly. Journal of Applied Gerontology, 11(2), 216-227. https://doi. org/10.1177/073346489201100207.

Jones, L., \& Heley, J. (2016). Practices of participation and voluntarism among older people in rural Wales: Choice, obligation and constraints to active ageing. Sociologia Ruralis, 56(2), 176-196. https://doi.org/10.1111/soru.12073.

Kruse, A., \& Schmitt, E. (2015). Shared responsibility and civic engagement in very old age. Research in Human Development, 12(1-2), 133-148. https://doi.org/10.1080/15427609.201 5.1010353.

Levitas, R., Pantazis, C., Fahmy, E., Gordon, D., Lloyd, E., \& Patsios, D. (2007). The multidimensional analysis of social exclusion. London. https://doi.org/10.1177/1744987110370529.

Martinez, I., Crooks, D., Kim, K., \& Tanner, E. (2011). Invisible civic engagement among older adults: Valuing the contributions of informal volunteering. Journal of Cross-Cultural Gerontology, 26(1), 23-37. https://doi.org/10.1007/s10823-011-9137-y.

Martinson, M., \& Halpern, J. (2011). Ethical implications of the promotion of elder volunteerism: A critical perspective. Journal of Aging Studies, 25(4), 427-435. https://doi.org/10.1016/j. jaging.2011.04.003.

Morrow-Howell, N., \& Mui, A. (2012). Productive engagement in later life: A global perspective. New York: Routledge.

Morrow-Howell, N., Hong, S. I., \& Tang, F. (2009). Who benefits from volunteering? Variations in perceived benefits. The Gerontologist, 49(1), 91-102. https://doi.org/10.1093/geront/gnp007.

Nesteruk, O., \& Price, C. (2011). Retired women and volunteering: The good, the bad, and the unrecognized. Journal of Women \& Aging, 23(2), 99-112. https://doi.org/10.1080/0895284 1.2011.561138. 
Nygård, M., \& Jakobsson, G. (2013). Senior citizens and political participation: Evidence from a Finnish regional study. Ageing \& Society, 33(1), 159-180. https://doi.org/10.1017/ S0144686X11001139.

Offe, C. (1985). New social movements: Challenging the boundaries of institutional politics. Social Research, 52(4), 817-868.

Petriwskyj, A., Warburton, J., Everingham, J., \& Cuthill, M. (2014). Seniors' motivations for participation in local governance: Evidence from an Australian study. Local Government Studies, 40(2), 240-263. https://doi.org/10.1080/03003930.2013.790812.

Petriwskyj, A., Serrat, R., Warburton, J., Everingham, J., \& Cuthill, M. (2017). Barriers to older people's participation in local governance: The impact of diversity. Educational Gerontology, 43(5), 259-275. https://doi.org/10.1080/03601277.2017.1293391.

Piercy, K. W., Cheek, C., \& Teemant, B. (2011). Challenges and psychosocial growth for older volunteers giving intensive humanitarian service. The Gerontologist, 51(4), 550-560. https:// doi.org/10.1093/geront/gnr013.

Postle, K., Wright, P., \& Beresford, P. (2005). Older people's participation in political activity making their voices heard: A potential support role for welfare professionals in countering ageism and social exclusion. Practice, 17(3), 173-189. https://doi.org/10.1080/09503150500285123.

Principi, A., Jensen, P., \& Lamura, G. (2014). Active ageing: Voluntary work by older people in Europe. Bristol: The Policy Press.

Principi, A., Galenkamp, H., Papa, R., Socci, M., Suanet, B., Schmidt, A., et al. (2016). Do predictors of volunteering in older age differ by health status? European Journal of Ageing, 13(2), 91-102. https://doi.org/10.1007/s10433-016-0377-0.

Schwarz, C. H. (2019). Collective memory and intergenerational transmission in social movements: The "grandparents' movement" iaioflautas, the indignados protests, and the Spanish transition. Memory Studies. https://doi.org/10.1177/1750698019856058.

Serrat, R., \& Villar, F. (2019). Lifecourse transitions and participation in political organisations in older Spanish men and women. Ageing \& Society, 40, 2174-2190. https://doi.org/10.1017/ S0144686X19000618.

Serrat, R., Warburton, J., Petriwskyj, A., \& Villar, F. (2018). Political participation and social exclusion in later life: What politically active seniors can teach us about barriers to inclusion and retention. International Journal of Ageing and Later Life, 12, 53-58. https://doi.org/10.3384/ ijal.1652-8670.18395.

Serrat, R., Scharf, T., Villar, F., \& Gómez, C. (2019). Fifty-five years of research into older people's civic participation: Recent trends, future directions. The Gerontologist, 60, e38-e51. https:// doi.org/10.1093/geront/gnz021.

Skinner, M., \& Hanlon, N. (2015). Ageing resource communities: New frontiers of rural population change, community development and voluntarism. London: Routledge.

Stone, M. E., Lin, J., Dannefer, D., \& Kelley Moore, J. A. (2017). The continued eclipse of heterogeneity in gerontological research. The Journals of Gerontology Series B: Psychological Sciences and Social Sciences, 72(1), 162-167. https://doi.org/10.1093/geronb/gbv068.

Tang, F., Morrow-Howell, N., \& Hong, S. (2009). Inclusion of diverse older populations in volunteering: The importance of institutional facilitation. Nonprofit and Voluntary Sector Quarterly, 38(5), 810-827. https://doi.org/10.1177/0899764008320195.

Theocharis, Y. (2015). The conceptualization of digitally networked participation. Social Media + Society, 1(2), 1-14. https://doi.org/10.1177/2056305115610140.

Torres, S., \& Serrat, R. (2019). Older migrants' civic participation: A topic in need of attention. Journal of Aging Studies, 50. https://doi.org/10.1016/j.jaging.2019.100790.

United Nations. (2002). Madrid international plan of action on ageing. Madrid.

van Deth, J. W. (2001). Studying political participation: Towards a theory of everything? European Consortium for Political Research, 1-19.

Walsh, K., Scharf, T., \& Keating, N. (2017). Social exclusion of older persons: A scoping review and conceptual framework. European Journal of Ageing, 14(1), 81-98. https://doi.org/10.1007/ s10433-016-0398-8. 
Warburton, J., \& Jeppsson Grassman, E. (2011). Variations in older people's social and productive ageing activities across different social welfare regimes. International Journal of Social Welfare, 20(2), 180-191. https://doi.org/10.1111/j.1468-2397.2009.00691.x.

Warburton, J., \& Winterton, R. (2017). A far greater sense of community: The impact of volunteer behaviour on the wellness of rural older Australians. Health and Place, 48, 132-138. https:// doi.org/10.1016/j.healthplace.2017.10.005.

WHO. (2002). Active ageing: A policy framework. Geneva.

Young, I. M. (2000). Inclusion and democracy. New York: Oxford University Press.

Open Access This chapter is licensed under the terms of the Creative Commons Attribution 4.0 International License (http://creativecommons.org/licenses/by/4.0/), which permits use, sharing, adaptation, distribution and reproduction in any medium or format, as long as you give appropriate credit to the original author(s) and the source, provide a link to the Creative Commons license and indicate if changes were made.

The images or other third party material in this chapter are included in the chapter's Creative Commons license, unless indicated otherwise in a credit line to the material. If material is not included in the chapter's Creative Commons license and your intended use is not permitted by statutory regulation or exceeds the permitted use, you will need to obtain permission directly from the copyright holder. 